\title{
Perencanaan Wireless Metropolitan Area Network Kota Tarakan
}

\author{
Hatim Husyaini ${ }^{1}$, Rudy ${ }^{2}$ \\ ${ }^{1,2}$ Program Studi Teknik Elektro, Universitas Borneo Tarakan \\ Jl.Amal Lama No.1 Tarakan, Indonesia \\ ${ }^{2}$ rudy@borneo.ac.id
}

\begin{abstract}
This research uses a star network topology on the network backhaul. At this backhaul network using $5.8 \mathrm{GHz}$ WiMAX technology this is due to deliver bandwidth at high speed so that it can provide a good internet connection and fast. Then the $5.8 \mathrm{GHz}$ WiMAX network is converted to $2.4 \mathrm{GHz}$ network which is then channeled to the areas with the method of point to multipoint.

The result of this research, cells in the WiFi communication hannel optimized results is to utilize six existing towers and of all the results of link budget calculations on each network then optimal results that meet the applicable standards and regulations in Indonesia so that the user can be connected properly.
\end{abstract}

Intisari-Penelitian ini menggunakan metode topologi jaringan bintang pada jaringan backhaul. Pada jaringan backhaul ini menggunakan teknologi WiMAX 5,8 GHz hal ini dikarenakan agar dapat menghantarkan bandwidth dengan kecepatan tinggi sehingga dapat menyediakan koneksi internet yang baik dan cepat. Kemudian jaringan WiMAX 5,8 GHz ini dikonversi ke jaringan $2,4 \mathrm{GHz}$ yang kemudian disalurkan ke daerah-daerah dengan metode point to multipoint.

Dari hasil penelitian, sel-sel kanal komunikasi WiFi didapatlah hasil yang optimal yaitu dengan memanfaatkan 6 menara yang sudah ada dan dari semua hasil perhitungan link budget pada setiap jaringan maka didapatlah hasil yang optimal yang telah memenuhi standar dan peraturan yang berlaku di Indonesia sehingga para pengguna dapat terkoneksi dengan baik.

Kata Kunci- WiMAX, WiFi, backhaul, MAN, Tarakan

\section{PEndahuluan}

Sesuai dengan perkembangan zaman, internet sudah menjadi salah satu kebutuhan utama manusia. Semakin hari akan semakin banyak teknologi pendukung yang mengarah pada cara-cara koneksi internet. Awalnya koneksi internet dimulai dari kabel yaitu dial-up dan ADSL (Asymmetric Digital Subcriber Line) kemudian menggunakan teknologi nirkabel (wireless) dan dikembangkan lagi dengan menggunakan teknologi WiMAX (Worldwide Interoperability for Microwave Access).

WLAN (Wireless Local Area Network) 2,4 GHz menjadi teknologi alternatif dan relatif lebih mudah diimplementasikan di lingkungan kerja serta lebih murah dibandingkan dengan menggunakan kabel. Teknologi nirkabel ini juga merupakan salah satu bentuk pemanfaatan teknologi pada lokasi-lokasi publik seperti taman, restoran, kafe, kampus, sekolah, bandara perkantoran bahkan sampai ke rumah-rumah. Koneksi internet biasanya menggunakan Notebook/Laptop/PDA/HP/I-Pad. Pada umumnya, nirkabel memiliki standar, yang ditetapkan oleh badan internasional yang bernama Institut of Electrical and Electronic Engineers (IEEE), yang secara umum adalah IEEE 802.11a, IEEE 802.11b, IEEE 802.11g dan IEEE 802.11n. Teknologi nirkabel ini mampu memberikan kecepatan akses yang tinggi antara $11 \mathrm{Mbps}$ sampai dengan 54 Mbps. WiMAX merupakan Standar BWA (Broadband Wireless Access) dengan kemampuan menyediakan layanan data berkecepatan tinggi. Teknologi WiMAX merupakan pengembangan dari teknologi Wi-Fi (Wireless Fidelity) yang didesain untuk kondisi N-LOS (Non-Line of Sight). Untuk teknologi WiMAX ini memiliki kecepatan hingga 70 Mbps dan jarak jangkauannya hingga $50 \mathrm{~km}$.

Menyikapi kenyataan diatas, maka untuk kedepannya jaringan nirkabel ini lambat laun akan semakin banyak digunakan oleh manusia seperti chat, email, tv streaming, video call, video email, game online, jejaring sosial dan lain sebagainya, sehingga dibutuhkan lebar pita (bandwidth) yang besar, maka pada penelitian ini akan dicoba merencanakan jaringan internet di kota Tarakan yang berupa WMAN (Wireless Metropolitan Area Network) dengan menggunakan teknologi WiMAX 5,8 GHz sebagai jaringan utama (backhaul) dan kemudian di salurkan ke daerah-daerah dengan memanfaatkan antena yang sudah ada dengan menggunakan frekuensi 2,4 GHz, agar dapat digunakan untuk kantor-kantor pemerintahan maupun swasta, sekolah, kampus dan fasilitas umum lainnya, sehingga dapat membantu program pemerintah dalam mewujudkan kota Tarakan menjadi kota pendidikan, Tarakan little Singapore dan Tarakan sebagai Cyber City.

Adapun rumusan masalah pada penelitian ini adalah :

Bagaimana merencanakan sel-sel kanal komunikasi WiFi yang optimal pada wilayah kota Tarakan dengan memanfaatkan menara yang sudah ada.

Bagaimana memperhitungkan link budget pada jaringan backhaul.

Bagaimana menentukan luasan pada setiap sel.

Bagaimana mendesain perencanaan yang telah diperhitungkan

Tujuan dari perencanaan WMAN ini yaitu untuk merencanakan sebuah jaringan yang memiliki lebar pita yang besar serta untuk membuat penataan sel-sel kanal komunikasi WMAN yang optimal pada daerah kota Tarakan, sehingga dapat menjangkau seluruh daerahdaerah yang merupakan daerah pemukiman, perkantoran, kampus dan fasilitas umum lainnya dengan memanfaatkan menara yang sudah. 
Adapun batasan masalah dalam pengerjaan peneltian ini yaitu tidak memperhitungkan pengalokasian lebar pita serta pengguna (user) dan dalam pengukuran menggunakan aplikasi Google Earth dan Radio Mobile.

\section{TINJAUAN PUSTAKA}

Cara paling mudah untuk memenuhi persyaratan format penulisan adalah dengan menggunakan dokumen ini sebagai template. Kemudian ketikkan teks Anda ke dalamnya

\section{Wireless Local Area Network (WLAN)}

Wireless Local Area Network (WLAN) merupakan teknologi wireless yang sekarang mulai banyak digunakan di Indonesia, teknologi ini selain murah dapat juga digunakan sebagai pengganti media kabel. WLAN merupakan teknologi akses dalam komunikasi data yang menggunakan gelombang mikro sebagai media transmisinya dan modulasi spread spectrum untuk menambah kapasitas lebar pita dari sinyal informasi yang dikirim. Teknologi WLAN memiliki 3 frekuensi kerja yaitu : $915 \mathrm{MHz}, 2,4 \mathrm{GHz}$ dan 5,8 GHz. Untuk WLAN 2,4 GHz, alokasi spektrumnya berbeda antar negara di dunia.

\section{Worldwide Interoperability for Microwave Access (WiMAX)}

Teknologi WiMAX adalah teknologi yang sedang hangat dibicarakan dan diklaim sebagai teknologi $4 \mathrm{G}$ masa depan. WiMAX merupakan standar Broadband Wireless Access dengan kemampuan menyediakan layanan data berkecepatan tinggi. Teknologi WiMAX merupakan pengembangan dari teknologi Wi-Fi yang didesain untuk kondisi N-LOS (NonLine of Sight).

WiMAX menggunakan standar IEEE 802.16 yang ditetapkan oleh IEEE. WiMAX termasuk dalam kategori WMAN (Wireless Metropolitan Area Network) yang memiliki laju data mencapai $70 \mathrm{Mbps}$ dan dapat menjangkau sampai 50 $\mathrm{km}$. WMAN dapat mencakup sebuah kota yang besar.

\section{Line of Sight (LOS),}

Line of Sight (LOS), sangat mudah untuk dimengerti jika berbicara tentang cahaya tampak. untuk melihat titik B dari titik A tidak ada penghalang antara A dan B, maka kita mempunyai LOS.

Konsep Line of Sight menjadi lebih kompleks jika kita menggunakan gelombang mikro, karena sebagian besar karakteristik perambatan dari gelombang elektromagnetik tergantung pada panjang gelombangnya. Hal ini mirip dengan pelebaran gelombang pada saat gelombang tersebut berjalan. Panjang gelombang cahaya sekitar 0,5 mikrometer, sementara gelombang mikro yang kita gunakan dalam jaringan wireless mempunyai panjang gelombang beberapa centimeter. Konsekuensinya, pancaran gelombang mikro akan lebih lebar atau secara sederhana gelombang mikro membutuhkan ruang / jalan yang lebih lebar. Perlu dicatat bahwa pancaran cahaya tampak juga akan melebar seperti yang terjadi pada gelombang mikro. Jadi LOS yang dibutuhkan agar dapat terjadi sambungan wireless yang optimal antara A dan B yang menyamai lintasan elips. Lintasan tersebut dikenal sebagai konsep fresnel zone.

Fresnel zone adalah suatu daerah pada suatu lintasan transmisi gelombang mikro yang digambarkan berbentuk elips. Teori fresnel zone melihat garis lurus antara $\mathrm{A}$ dan $\mathrm{B}$, dan ruang di sekitar garis lurus tersebut untuk melihat apa yang akan terjadi pada saat sinyal sampai di B. Beberapa gelombang akan merambat langsung dari A ke B, beberapa lainnya akan merambat keluar garis lurus. Akibatnya jalur yang di tempuh menjadi lebih panjang, hal ini menimbulkan perbedaan fasa antara sinyal yang langsung dengan yang tidak langsung.

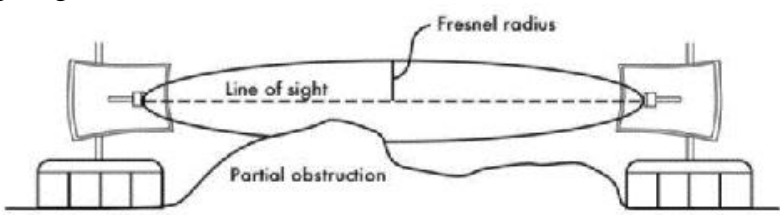

\section{Gambar 2.1 Fresnel zone}

Teori difraksi menunjukkan bahwa jalur langsung antara pemancar dan penerima, jarak ruang (clearance) di atas tanah minimal $60 \%$ dari radius zona Fresnel pertama untuk mencapai kondisi ruang bebas hambatan.

Fresnel zone dapat dihitung dengan persamaan sebagai berikut:

$F-1 /, 31 \sqrt{\frac{\left(d_{1} \times d_{2}\right)}{f x d}}$

dimana :

$\mathrm{F}=$ Fresnel zone $(\mathrm{km})$

$d_{1}$ dan $d_{2}=$ jarak dari penghalang di kedua ujung menara $(\mathrm{km})$

$f=$ frekuensi $(\mathrm{GHz})$

$d=\operatorname{jarak}(\mathrm{km})$

\section{Jenis Perancangan Jaringan}

Dalam perancangan jaringan nirkabel ada tiga macam konfigurasi logis yaitu point to point, point to multipoint dan multipoint to multipoint.

- $\quad$ Point to Point

Konfigurasi point to point biasanya menyediakan sebuah koneksi internet dimana akses lain tidak tersedia. Satu sisi dari sambungan point to point memiliki koneksi internet, sementara yang lain menggunakan sambungan tersebut untuk mencapai Internet. Dengan antena yang tepat dan kondisi LOS, maka sambungan point to point untuk jarak $30 \mathrm{~km}$ bisa terjadi.

- Point to Multipoint

Tata letak jaringan yang sering dihadapi adalah point to multipoint. Apabila beberapa simpul terkoneksi ke pusat akses, ini merupakan aplikasi point to multipoint.

- Multipoint to Multipoint

Multipoint to multipoint disebut juga sebagai ad-hoc atau jaringan mesh. Dalam jaringan multipoint to multipoint, tidak ada kewenangan pusat. Setiap simpul pada jaringan dapat membawa lalu lintas data dari setiap simpul lainnya yang 
memerlukan dan semua simpul berkomunikasi satu sama lain secara langsung.

\section{Perhitungan Link Budget}

Perhitungan link budget adalah perhitungan kasar seluruh elemen dari transmisi sinyal untuk memperkirakan kuat sinyal yang dapat diterima di sisi penerima nantinya. Dalam perhitungan link budget hal-hal yang perlu diperhatikan adalah :

\section{Daya pancar $\left(P_{T}\right)$}

Dinyatakan dalam milliwatts atau $\mathrm{dBm}$. Daya pemancar berkisar $30 \mathrm{~mW}$ sampai $200 \mathrm{~mW}$ atau lebih. Di Indonesia, ada peraturan yang membatasi untuk menggunakan maksimum $\mathrm{P}_{\mathrm{T}}$ yaitu sebesar $100 \mathrm{~mW}(20 \mathrm{dBm})$. (Pasal 6 ayat b, KM. 2 Tahun 2005)

\section{Penguatan Antena (Gain)}

Antena diperlukan jika kita memasang infrastruktur jaringan tanpa kabel untuk outdoor. Antena akan mengubah dari sinyal listrik ke sinyal elektromagnetik. Jumlah energi yang dapat dikuatkan oleh antena pada sisi penerima atau pengirim disebut dengan antena gain. Untuk antena parabola mempunyai penguatan antara 19 24 dBi, untuk antena omnidirectional mempunyai penguatan antara 5 12 dBi dan antena sektoral yang memiliki penguatan antena antara 12 15 $\mathrm{dBi}$.

\section{RSL (Receive Signal Level)}

RSL (Receive Signal Level) atau sensitifitas dari penerima. Minimum RSL selalu dinyatakan sebagai $\mathrm{dBm}$ negatif (-) $\mathrm{dBm}$. Minimum RSL biasanya dalam kisaran antara -75 sampai $-95 \mathrm{dBm}$. Seperti $P_{T}$, spesifikasi RSL harus disediakan oleh pabrik pembuat peralatan. RSL dapat dihitung dengan persamaan berikut :

$$
\begin{aligned}
& R S L=F_{T}+G_{T}-L_{T}-L_{\text {Path }}+G_{R}-L_{R} \\
& \text { dimana : } \\
& R S L=\text { Sensitifitas penerima }(\mathrm{dB}) \\
& P_{T}=\text { Daya pancar }(\mathrm{dBm}) \\
& G_{T}=\text { Penguatan antena pemancar }(\mathrm{dBi}) \\
& L_{T}=\text { Rugi-rugi saluran pemancar }(\mathrm{dB}) \\
& G_{R}=\text { Penguatan antena penerima }(\mathrm{dBi}) \\
& L_{R}=\text { Rugi-rugi saluran penerima }(\mathrm{dB}) \\
& L_{P a \tau n}=\text { Jumlah redaman }(\mathrm{FSL}+\text { Redaman Hujan })(\mathrm{dB})
\end{aligned}
$$

\section{SOM (System Operating Margin)}

SOM System Operating Margin atau biasa disebut juga sebagai Fade Margin. Suatu margin sistem operasi yang digunakan agar aman dari gangguan radio seperti fading dan multipath.

Catatan:
- Excellent: Link harus bekerja dengan kehandalan yang tinggi, ideal untuk aplikasi yang menuntut kualitas link tinggi. Fade Margin tingkat lebih dari $22 \mathrm{~dB}$.

- Good: Link harus memberikan browser yang baik. Tingkat Margin Fade adalah $14 \sim 22$ dB.

- Normal: Link tidak akan stabil sepanjang waktu, tetapi harus bekerja dengan baik. Tingkat Margin Fade adalah $14 \mathrm{~dB}$ atau lebih rendah.

Agar sistem dapat bekerja dengan baik maka sebaiknya nilai SOM minimal sebesar $15 \mathrm{~dB}$.

Persamaan untuk SOM adalah sebagai berikut :

$S O M=R S L-R x$ Sensitivity

\section{Redaman pada Kabel (L)}

Beberapa energi sinyal akan hilang di kabel, di konektor atau pada perangkat lain, pada saat sinyal merambat dari radio ke antena. Hilangnya tergantung pada jenis kabel dan panjangnya. Kerugian sinyal untuk coaxial kabel pendek termasuk konektornya biasanya cukup rendah, yang berkisar antara 2-3 dB. Akan lebih baik untuk memiliki kabel sependek mungkin.

\section{Redaman pada Kabel $(L)$}

Beberapa energi sinyal akan hilang di kabel, di konektor atau pada perangkat lain, pada saat sinyal merambat dari radio ke antena. Hilangnya tergantung pada jenis kabel dan panjangnya. Kerugian sinyal untuk coaxial kabel pendek termasuk konektornya biasanya cukup rendah, yang berkisar antara 2-3 dB. Akan lebih baik untuk memiliki kabel sependek mungkin.

\section{METODE PENELITIAN}

Dalam perencanaan jaringan WMAN di kota Tarakan, metode penelitian meliputi tahapan perencanaan seperti pada gambar 3.1.

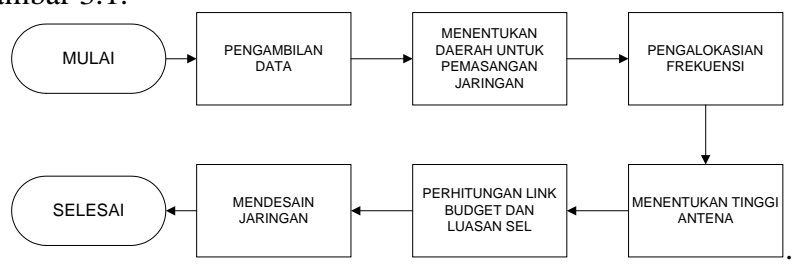

Gambar 3.1 Flowchart Metode Perencanaan

\section{Pengambilan Data}

Untuk keperluan penelitian ini maka memerlukan data-data sebagai berikut :

Letak geografis pada masing-masing menara

Tinggi menara

Luas daerah

Ketinggian daerah

\section{Menentukan Daerah untuk Pemasangan Jaringan}

Dalam perencanaan ini, tidak semua daerah kota Tarakan dapat dipasang jaringan wireless, hal ini dikarenakan masih 
banyak daerah yang merupakan hutan lindung dan tidak berpenduduk. Sehingga dalam perencanaan ini penulis hanya akan memasang jaringan wireless di daerah perkotaan, pemukiman penduduk, perkantoran pemerintah maupun swasta, pabrik, sekolah-sekolah, kampus, pelabuhan dan daerah yang direncanakan oleh pemerintah dalam pengembangan kota Tarakan.

\section{Pengalokasian Frekuensi dan Kanal}

Pengalokasian frekuensi dan kanal sangat perlu dilakukan agar sistem yang dibangun tidak saling menginterfensi satu sama yang lainnya.

\section{Pengalokasian frekuensi $5,8 \mathrm{GHz}$}

Untuk menghindari adanya interferensi pada jaringan backhaul, maka akan digunakan kanal 1, 10 dan 20, hal ini dikarenakan kanal tersebut memiliki jarak yang cukup jauh sehingga tidak terjadi interferensi pada setiap jaringan backhaul.

\section{Pengalokasian frekuensi $2,4 \mathrm{GHz}$}

Untuk menghindari adanya interfensi dalam perencanaan WLAN 2,4 GHz dan juga untuk mempermudah pembagian letak kanal-kanal, maka akan menggunakan kanal 1, kanal 6 dan kanal 11, hal ini dikarenakan kanal tersebut tidak saling overlap, sehingga tidak terjadi interfensi antar menara.

\section{Menentukan Tinggi Antena}

Dalam menentukan tinggi antena minimal agar antara sel A dan sel B tetap dalam kondisi LOS (Line Of Sight) dan berada pada daerah Fresnel, maka akan menggunakan Persamaan 2.1, 2.2, 2.3 dan 2.4 seperti yang terdapat pada BAB 2 .

\section{Perhitungan Link Budget dan Luasan Sel}

\section{Pemilihan Jenis Antena}

Sebelum melakukan perhitungan dalam perencanaan ini, penulis akan menentukan jenis antena yang akan digunakan dalam perencanaan jaringan ini agar dapat mengetahui nilai penguatan antena (gain) sehingga dapat mempermudah dalam perhitungan link budget pada setiap sel.

\section{Untuk jaringan WiMAX}

Pada jaringan WiMAX ini jenis antena yang digunakan adalah jenis antena parabola karena antena parabola ini sangat cocok untuk jaringan backhaul, pada sisi pengirim dalam perencanaan ini akan menggunakan antena "29 dBi ISM / UNII Band Solid Parabolic Dish Antenna”. Spesifikasi alat :

$\begin{array}{ll}\text { Frekuensi } & : 5725-5850 \mathrm{MHz} \\ \text { Gain } & : 29 \mathrm{dBi} \\ \text { Daya Max. } & : 100 \text { Watt }\end{array}$

Pada sisi penerima, antena yang akan digunakan adalah antenna Grid “TDJ-5800SPL9”. Spesifikasi alat :

$\begin{array}{ll}\text { Frekuensi } & : 5725-5850 \mathrm{MHz} \\ \text { Gain } & : 30 \mathrm{dBi} \\ \text { Daya Max. } & : 100 \mathrm{Watt}\end{array}$

Untuk jaringan Wireless
Pada jaringan wireless ini, ada dua jenis antena yang akan digunakan dalam perencanaan ini yaitu antena omnidirectional, antena sektoral $120^{\circ}$ dan antena Grid. Dimana antena omnidirectional dengan spesifikasi alat :

$$
\begin{array}{ll}
\text { Frekuensi } & : 2400-2500 \mathrm{MHz} \\
\text { Gain } & : 15 \mathrm{dBi} \\
\text { Daya Max. } & : 100 \mathrm{Watt}
\end{array}
$$

Antena sektoral dengan spesifikasi alat :

$$
\begin{array}{ll}
\text { Frekuensi } & : 2400-2500 \mathrm{MHz} \\
\text { Gain } & : 14 \mathrm{dBi} \\
\text { Daya Max. } & : 100 \mathrm{Watt}
\end{array}
$$

Frekuensi : $2400-2835 \mathrm{MHz}$

$$
\text { Gain } \quad: 24 \mathrm{dBi}
$$

Daya Max. : 100 Watt

Dan antena grid dengan spesifikasi alat :

Frekuensi : $2400-2835 \mathrm{MHz}$

Gain $\quad: 24 \mathrm{dBi}$

Daya Max. : 100 Watt

Antena-antena ini digunakan sebagai antena yang langsung digunakan ke konsumen (user).

\section{Perhitungan untuk Jaringan WiMAX}

Dalam perencanaan ini, terdapat hal-hal yang perlu diperhitungkan agar sebuah jaringan bisa terkoneksi dengan baik, yaitu dengan memperhitungkan hal-hal sebagai berikut :

a. Perhitungan Redaman

- Redaman hujan ( $\left.\mathrm{A}_{\text {reff }}\right)$

Dalam perhitungan redaman hujan, hanya frekuensi yang diatas $4 \mathrm{GHz}$ saja yang akan mengalami redaman. Sehingga untuk perhitungan jaringan backhaul $5,8 \mathrm{GHz}$.

- Redaman ruang bebas (FSL)

Dalam perhitungan Redaman ruang bebas pada jaringan backhaul 5,8 GHz.

- Redaman pada kabel

Redaman kabel ditentukan oleh jenis kabelnya, dalam perencanaan ini menggunakan tipe LMR400 dengan nilai redaman kabel sebesar $0,35 \mathrm{~dB} / \mathrm{m}$ dan redaman pada konektor sebesar $0,5 \mathrm{~dB}$.

b. Perhitungan Link Budget

- $\quad$ Menghitung RSL (Receive Signal Level)

Untuk menghitung nilai RSL pada jaringan backhaul 5,8 $\mathrm{GHz}$, maka menggunakan persamaan 2.5 yang terdapat pada bab sebelumnya.

- $\quad$ Menghitung EIRP rancang

Untuk menghitung nilai EIRP rancang pada jaringan backhaul $5,8 \mathrm{GHz}$, maka menggunakan persamaan sebagai berikut :

$$
E I R P=F S L+L_{h u j z n}+R S L-G_{R}+L_{R}
$$

\section{Perhitungan untuk Jaringan WiFi}

- Redaman Kabel

Redaman kabel ditentukan oleh jenis kabelnya, dalam perencanaan ini menggunakan tipe LMR400 dengan nilai redaman pada kabel sebesar $0,22 \mathrm{~dB} / \mathrm{m}$ dan redaman pada konektor sebesar 0,5 dB.

- Menghitung RSL (Receive Signal Level) 
Untuk menghitung nilai RSL pada jaringan WiFi 2,4 GHz, maka akan menggunakan persamaan berikut :

$$
\begin{aligned}
& S O M-R S L-R \times \text { SErisilif } \\
& R S L=5 O M-R \times \text { Sensitif }
\end{aligned}
$$

- Menghitung redaman ruang bebas (FSL)

Untuk menghitung nilai FSL pada jaringan WiFi 2,4 GHz, maka akan menggunakan persamaan

$$
F S L=F_{T}+G_{T}-L_{T}+G_{R}-L_{R}-R S L-S O M
$$

- Jarak

Untuk menghitung jarak jangkauan pada jaringan wireless 2,4 GHz, maka akan menggunakan pada FSL yaitu : $F S L(d B)=32,45+20 \log f(\mathrm{lHz})+20 \log d(\mathrm{~km})$

$$
\begin{aligned}
& \log d(\mathrm{~km})=\frac{F S L(d B)-20 \log f(M H z)-32,45}{20} \\
& d=10 \frac{\text { FSL (dB })-20 \log f(M H z)-32,45}{20}
\end{aligned}
$$

- $\quad$ Luasan sel

Untuk menghitung luas sel, maka menggunakan persamaan Luas sel $=\pi d^{2}$. Luas sel $=2,598 x d^{2}$

\section{HASIL DAN PEMBAHASAN}

\section{Analisa Peta Tarakan}

Daerah Tarakan yang letak geografisnya $3^{\circ} 14^{\prime} 23^{\prime \prime}$ $3^{\circ} 26^{\prime} 37^{\prime \prime}$ LU dan $117^{\circ} 30^{\prime} 50^{\prime \prime}$ - 117 $47^{\circ} 12^{\prime \prime}$ BT dan memiliki luas daratan $250,80 \mathbf{~ k m}^{2}$ serta luas lautannya $406,53 \mathbf{~ k m}^{2}$. Pada perhitungan dalam perencanaan ini maka akan dibagi dalam perkecamatan dengan memanfaatkan menara yang sudah ada disetiap kecamatan dengan menentukan daerahdaerah mana saja yang akan dipasang jaringan nirkabel.

\section{Kecamatan Tarakan Tengah}

Di daerah kecamatan Tarakan Tengah memiliki Luas daerah 55,54 $\mathrm{km}^{2}$. Daerah di kecamatan Tarakan Tengah banyak terdapat pemukiman penduduk, sekolah-sekolah, perkantoran pemerintah maupun swasta. Dalam perencanan ini, tidak semua daerah kecamatan Tarakan Tengah yang akan dipasang jaringan wireless, karena sebagian daerah kecamatan Tarakan Tengah masih merupakan hutan lindung dan tidak berpenduduk, sehingga yang dipasang hanya di daerah pemukiman penduduk, sekolah-sekolah, kampus, rumah sakit, perkantoran pemerintah maupun swasta dan fasilitas umum seperti taman oval. Menara yang akan digunakan dalam perencanaan WMAN adalah menara TVRI yang terletak di daerah gunung belah yang letak geografisnya $3^{\circ} 18^{\prime} 41^{\prime} 91^{\prime \prime} \mathrm{LU}$ dan $117^{\circ} 36^{\prime} 7.95^{\prime \prime} \mathrm{BT}$, dengan menara setinggi $88 \mathrm{~m}$ dan berada pada ketinggian 46,2 mdpl. Menara TVRI ini dimanfaatkan sebagai jaringan backhaul dan dimanfaatkan juga untuk jaringan nirkabelnya, hal ini dikarenakan menara ini berada di tempat yang sangat strategis yang dapat mencapai seluruh daerah kota Tarakan dan menara ini juga merupakan menara tertinggi yang ada di kota Tarakan.

\section{Kecamatan Tarakan Barat}

Di daerah kecamatan Tarakan Barat memiliki luas daerah $27,89 \mathrm{~km}^{2}$. Daerah di kecamatan Tarakan Barat ini merupakan daerah pusat kota pada saat ini dimana banyak terdapat pemukiman penduduk, sekolah-sekolah, perkantoran pemerintah maupun swasta, bandara, mall dan lain-lain. Menara yang akan digunakan di daerah ini adalah menara yang berada di daerah SMKN 2 Tarakan, yang letak geografisnya $3^{\circ} 20^{\prime} 20.68^{\prime \prime}$ LU dan $117^{\circ} 34^{\prime} 22.00^{\prime \prime}$ BT, dengan menara setinggi $30 \mathrm{~m}$ dan terletak pada ketinggian 22,2 mdpl.

\section{Kecamatan Tarakan Timur}

Di daerah kecamatan Tarakan Timur ini memiliki luas daerah 58,01 $\mathrm{km}^{2}$. Daerah di kecamatan Tarakan Timur banyak terdapat pemukiman penduduk, sekolah-sekolah, kampus, pelabuhan, perkantoran pemerintah maupun swasta dan pabrik. Dalam perencaan ini di daerah kecamatan Tarakan Timur ini menggunakan dua buah menara yaitu menara di kantor Kecamatan Tarakan Timur dan BTS Pantai Amal yang berada di depan kampus Universitas Borneo Tarakan. Menara di kantor kecamatan Tarakan Timur yang memiliki letak geografisnya $3^{\circ} 17^{\prime} 55.26^{\prime \prime} \mathrm{LU}$ dan $117^{\circ} 37^{\prime} 26.47^{\prime \prime} \mathrm{BT}$, dengan menara setinggi $60 \mathrm{~m}$ dan terletak pada ketinggian $12,4 \mathrm{mdpl}$. Menara ini digunakan sebagai repeater dengan frekuensi 2,4 $\mathrm{GHz}$ yang mengambil sinyal dari sel TVRI dengan menggunakan antena grid, kemudian di pancarkan lagi dengan menggunakan dua buah antenna sektoral $120^{\circ}$. Hal ini dilakukan karena jarak yang cukup dekat yaitu sepanjang 3,28 $\mathrm{km}$, sehingga memungkinkan untuk menggunakan frekuensi 2,4 GHz. Kemudian untuk BTS Pantai amal yang letak geografisnya $3^{\circ} 18^{\prime} 9.11^{\prime \prime} \mathrm{LU}$ dan $117^{\circ} 38^{\prime} 59.46^{\prime \prime} \mathrm{BT}$, dengan menara setinggi $78 \mathrm{~m}$ dan berada pada ketinggian 22,5 mdpl. Menara ini digunakan karena berada di daerah kampus dan wisata.

\section{Kecamatan Tarakan Utara}

Di daerah kecamatan Tarakan Utara ini memiliki luas daerah 109,36 $\mathrm{km}^{2}$. Daerah di kecamatan Tarakan Utara banyak terdapat pemukiman penduduk, sekolah-sekolah, pelabuhan, perkantoran pemerintah maupun swasta dan pabrik. Di daerah kecamatan Tarakan Utara ini merupakan daerah yang akan dikembangkan oleh Pemerintah Kota Tarakan dimana pada saat ini masih dalam tahap perencanaan pengembangan, sehingga dalam perencanaan WMAN ini kecamatan Tarakan Utara akan dipasang jaringan Wireless. Pada perencanaan ini, daerah kecamatan Tarakan Utara akan menggunakan dua buah menara yaitu di kantor Kecamatan Tarakan Utara dan di kantor Kelurahan Juata Permai. Menara di kantor Kecamatan Tarakan Utara yang memiliki letak geogafis $3^{\circ} 25^{\prime} 3.67^{\prime \prime}$ LU dan 117³2'48.22" BT, dengan menara setinggi $75 \mathrm{~m}$ dan terletak pada ketinggian 15,8 mdpl. Kemudian menara di kantor Kelurahan Juata Permai memiliki letak geografisnya $117^{\circ} 32^{\prime} 48.22^{\prime \prime}$ BT dan $117^{\circ} 32^{\prime} 45.76^{\prime \prime}$ BT, dengan menara setinggi $54 \mathrm{~m}$ dan terletak pada ketinggian 30,4 mdpl. Kedua menara ini digunakan karena letaknya yang berada di daerah pengembangan kota Tarakan kedepannya, 
sehingga jaringan wireless ini sungguh sangat bermanfaat bagi daerah kecamatan Tarakan Utara untuk kedepannya

\section{Menentukan Tinggi Antena}

Dalam perencanaan ini semua link akan dikondisikan pada kondisi Line Of Sight. Maka akan digunakan perhitungan agar gelombang akan tetap merambat pada freznel zone sehingga kondisi Line Of Sight dapat tercapai. Untuk menentukan tinggi antena maka menggunakan persamaan 2.1, 2.2, 2.3 dan 2.4, dari hasil perhitungan tersebut, maka didapat tabel 4.1 sebagai berikut :

TABEL 4.1 TINGGI ANTENA MINIMAL UNTUK JARINGAN BACKHAUL

\begin{tabular}{|c|c|c|c|c|c|}
\hline No. & Menara & $\begin{array}{l}\text { Tinggi } \\
\text { Menara } \\
(\mathrm{m})\end{array}$ & $\begin{array}{l}\text { Letak } \\
\text { Ketinggian } \\
\text { Menara } \\
\text { (mdpal) }\end{array}$ & $\begin{array}{l}\text { Tinggi Antena } \\
\text { Minimal (m) }\end{array}$ & $\begin{array}{l}\text { Jarak } \\
(\mathrm{Km})\end{array}$ \\
\hline \multirow{2}{*}{1} & TVRI & & 46.2 & 37.90 & \multirow{2}{*}{13.65} \\
\hline & Kec. Tarakan Utara & 75 & 15.8 & 68.30 & \\
\hline \multirow{2}{*}{2} & TVRI & 88 & 46.2 & 25.50 & \multirow{2}{*}{6.08} \\
\hline & BTS Pantai Amal & 78 & 22.5 & 49.20 & \\
\hline \multirow{2}{*}{3} & TVRI & 88 & 46.2 & -12.25 & \multirow{2}{*}{4.55} \\
\hline & SMKN 2 & 30 & 22.1 & 11.85 & \\
\hline \multirow{2}{*}{4} & TVRI & 88 & 46.2 & -6.88 & \multirow{2}{*}{9.86} \\
\hline & Kel. Juata Permai & 54 & 30.4 & 8.92 & \\
\hline \multirow{2}{*}{5} & TVRI & 88 & 46.2 & -3.41 & \multirow{2}{*}{3.29} \\
\hline & Kec. Tarakan Timur & 60 & 12.5 & 30.39 & \\
\hline
\end{tabular}

Dari hasil tabel 4.1 diatas, dapat dijelaskan bahwa pada menara TVRI sebagai menara utama yang digunakan sebagai jaringan backhaul ke sel-sel lainnya yaitu sel kecamatan Tarakan Utara, sel BTS Pantai amal, sel SMKN 2, dan sel Juata Permai.

Untuk setiap tinggi antena yang hasil perhitungannya dibawah 20 m, maka letak menara akan ditetapkan setinggi 20 $\mathrm{m}$, hal ini dikarenakan agar setiap frekuensi yang dipancarkan tidak terhalang oleh pohon-pohon dan gedung yang ada disekitarnya, sehingga kondisi jaringan tetap dalam kondisi line of sight (LOS).

Untuk sel kecamatan Tarakan Timur, diperoleh tinggi antena minimal 30,39 meter, sel ini merupakan sel yang menggunakan frekuensi 2,4 GHz. Hal ini dilakukan karena di daerah sekitar sel kecamatan Tarakan Timur ini, merupakan daerah yang memiliki daerah yang kepadatannya penduduknya masih kurang, sehingga tidak membutuhkan lebar pita yang besar.

Perhitungan Link Budget untuk jaringan Backhaul Wimax

Dalam perhitungan link budget pada jaringan backhaul ini, ada beberapa hal penting yang harus diperhitungkan agar setiap sel dapat terkoneksi dengan baik. Hal-hal tersebut adalah sebagai berikut :

\section{Perhitungan Redaman}

Ada beberapa nilai redaman yang perlu diperhitungkan dalam perencanaan yaitu redaman hujan, redaman ruang bebas dan redaman pada kabel.

\section{Redaman Hujan (Precipitation)}

Indonesia terletak di daerah hujan $\mathrm{P}$, sehingga CCIR (Consultative Committee for International Radio) menetapkan curah hujan $\mathrm{R}$ adalah $145 \mathrm{~mm} / \mathrm{hr}$. untuk frekuensi kerja 5,8 $\mathrm{GHz}$, maka koefisien polarisasi vertikal adalah :
$\mathrm{f}=4 \mathrm{GHz}$
$\mathrm{a}_{\mathrm{v}}=0,00059$
$\mathrm{b}_{\mathrm{v}}=1,075$
$\mathrm{f}=6 \mathrm{GHz}$
$\mathrm{a}_{\mathrm{v}}=0,00155$
$b_{\mathrm{v}}=1,265$

dengan interpolasi $a_{v}$ dan $b_{v}$, pada frekuensi $5,8 \mathrm{GHz}$ dapat ditentukan :

$$
\begin{gathered}
\frac{a_{v}-0,00059}{0,00155-0,00059}=\frac{5,8-4}{6-4} \\
a_{v}=1,454 \times 10^{-3} \\
\frac{h_{z}-1,075}{1,255-1,075}=\frac{5,8-4}{6-4} \\
b_{v}=1,246
\end{gathered}
$$

Jadi untuk frekuensi 5,8 GHz didapat $\mathrm{a}_{\mathrm{v}}=1,454 \times 10^{-3}$ dan $\mathrm{b}_{\mathrm{v}}=1,246$, dari nilai tersebut maka dapat dimasukkan kedalam persamaan sebagai berikut:

$$
\begin{gathered}
A-u_{v} \times R^{h m}(u B / \mathrm{Km}) \\
A=1,454 \times 10^{-3} \times 145^{1,246} \\
A=0,71 \mathrm{~dB} / \mathrm{Km}
\end{gathered}
$$

\begin{tabular}{|c|c|c|c|c|}
\hline No. & Menara & $\begin{array}{l}\text { Jarak } \\
(\mathbf{K m}) \\
\end{array}$ & $\mathbf{r}$ & $\begin{array}{c}\text { L hujan } \\
\text { (dB) }\end{array}$ \\
\hline \multirow{2}{*}{1} & TVRI & \multirow{2}{*}{13.65} & \multirow{2}{*}{0.62} & \multirow{2}{*}{6.00} \\
\hline & Kec. Tarakan Utara & & & \\
\hline \multirow{2}{*}{2} & TVRI & \multirow{2}{*}{6.08} & \multirow{2}{*}{0.79} & \multirow{2}{*}{3.39} \\
\hline & BTS Pantai Amal & & & \\
\hline \multirow{2}{*}{3} & TVRI & \multirow{2}{*}{4.55} & \multirow{2}{*}{0.83} & \multirow{2}{*}{2.68} \\
\hline & SMKN 2 & & & \\
\hline \multirow{2}{*}{4} & TVRI & \multirow{2}{*}{9.86} & \multirow{2}{*}{0.69} & \multirow{2}{*}{4.85} \\
\hline & Kel. Juata Permai & & & \\
\hline
\end{tabular}

Dari hasil perhitungan diatas, maka didapat hasil perhitungan pada setiap jaringan backhaul tersebut tercantum pada tabel 4.2 dibawah ini.

TABEL 4.2 REDAMAN HUJAN

Dari hasil perhitungan yang tercantum pada tabel 4.2 diatas, maka dapat disimpulkan bahwa, semakin jauh jarak antar sel, maka semakin besar pula nilai redaman yang terdapat pada setiap jaringan.

\section{Redaman Ruang Bebas (Free Space Loss)}

Untuk perhitungan redaman ruang bebas (FSL), maka menggunakan persamaan 2.8, dimana hasil dari perhitungan dari setiap jaringan backhaul tersebut tercantum pada tabel 4.3. 
Dari hasil perhitungan pada tabel 4.3 diatas, maka semakin jauh jarak antar antena maka, semakin besar pula nilai redaman ruang bebasnya.

TABEL 4.3 REDAMAN RUANG BEBAS (FSL)

\begin{tabular}{|c|c|c|c|}
\hline No. & Menara & $\begin{array}{c}\text { Jarak } \\
(\mathrm{Km}) \\
\end{array}$ & $\begin{array}{l}\text { FSL } \\
(\mathrm{dB}) \\
\end{array}$ \\
\hline \multirow{2}{*}{1} & TVRI & \multirow{2}{*}{13.65} & \multirow{2}{*}{130.31} \\
\hline & Kec. Tarakan Utara & & \\
\hline \multirow{2}{*}{2} & TVRI & \multirow{2}{*}{6.08} & \multirow{2}{*}{123.35} \\
\hline & BTS Pantai Amal & & \\
\hline \multirow{2}{*}{3} & TVRI & \multirow{2}{*}{4.55} & \multirow{2}{*}{120.91} \\
\hline & SMKN 2 & & \\
\hline \multirow{2}{*}{4} & TVRI & \multirow{2}{*}{9.86} & \multirow{2}{*}{127.55} \\
\hline & Kel. Juata Permai & & \\
\hline
\end{tabular}

\section{Redaman pada kabel}

Untuk perhitungan redaman kabel pada perencanaan ini menggunakan tipe LMR400 dengan nilai redaman kabel sebesar $0,35 \mathrm{~dB} / \mathrm{m}$ dan redaman pada konektornya sebesar 0,5 dB. Kemudian nilai redaman pada setiap kabel dan konektor dapat dimasukkan kedalam persamaan 2.7, sehingga hasil dari semua redaman kabel pada setiap jaringan backhaul tercantum pada tabel 4.4 dibawah ini.

TABEL 4.4 REDAMAN KABEL PADA JARINGAN BACKHAUL

\begin{tabular}{|c|l|c|c|}
\hline \multirow{2}{*}{ No. } & \multicolumn{1}{|c|}{ Menara } & $\begin{array}{c}\text { Tinggi } \\
\text { Antena } \\
(\mathrm{m})\end{array}$ & $\begin{array}{c}\text { Redaman } \\
\text { Kabel } \\
(\mathrm{dB})\end{array}$ \\
\hline \multirow{2}{*}{1} & TVRI & 37.90 & 13.76 \\
\cline { 2 - 4 } & Kec. Tarakan Utara & 68.30 & 24.40 \\
\hline \multirow{2}{*}{2} & TVRI & 25.49 & 9.42 \\
\cline { 2 - 4 } & BTS Pantai Amal & 49.19 & 17.72 \\
\hline \multirow{2}{*}{3} & TVRI & 20.00 & 7.50 \\
\cline { 2 - 4 } & SMKN 2 & 20.00 & 7.50 \\
\hline \multirow{2}{*}{4} & TVRI & 20.00 & 7.50 \\
\cline { 2 - 4 } & Kel. Juata Permai & 20.00 & 7.50 \\
\hline
\end{tabular}

\section{Perhitungan Nilai RSL dan EIRP}

Pada perhitungan link budget ini nilai path loss merupakan nilai seluruh redaman yang ada pada jaringan backhaul yaitu redaman hujan dan redaman ruang bebas, dimana pada hasil perhitungan tersebut dapat dilihat pada tabel 4.5 dibawah ini.

TABEL 4.5 HASIL PERHITUNGAN LINK BUDGET PADA JARINGAN BACKHAUL

\begin{tabular}{|c|c|c|c|c|c|c|c|c|c|}
\hline \multirow[t]{2}{*}{ No. } & \multirow[t]{2}{*}{ Menara } & $\mathrm{PT}$ & G T & G R & $\mathrm{LT}$ & L R & $\begin{array}{c}\mathrm{L} \\
\text { path }\end{array}$ & RSL & EIRP \\
\hline & & $(\mathrm{dBm})$ & $(\mathrm{dBi})$ & $(\mathrm{dBi})$ & $(\mathrm{dB})$ & $(\mathrm{dB})$ & $(\mathrm{dB})$ & $(\mathrm{dB})$ & $(\mathrm{dBm})$ \\
\hline \multirow[b]{2}{*}{1} & TVRI & \multirow[b]{2}{*}{20} & \multirow[b]{2}{*}{29} & \multirow{2}{*}{30} & \multirow{2}{*}{13.76} & \multirow{2}{*}{24.40} & \multirow{2}{*}{$\begin{array}{l}136 . \\
31\end{array}$} & \multirow{2}{*}{-95.48} & \multirow[b]{2}{*}{29.23} \\
\hline & Kec. Tarakan Utara & & & & & & & & \\
\hline \multirow{2}{*}{2} & TVRI & \multirow{2}{*}{20} & \multirow{2}{*}{28} & \multirow{2}{*}{30} & \multirow{2}{*}{9.43} & \multirow{2}{*}{17.72} & \multirow{2}{*}{$\begin{array}{l}126 . \\
74\end{array}$} & \multirow{2}{*}{-75.89} & \multirow{2}{*}{35.18} \\
\hline & BTS Pantai Amal & & & & & & & & \\
\hline \multirow{2}{*}{3} & TVRI & \multirow{2}{*}{20} & \multirow{2}{*}{26} & \multirow{2}{*}{30} & \multirow{2}{*}{7.50} & \multirow{2}{*}{7.50} & \multirow{2}{*}{$\begin{array}{l}123 . \\
59\end{array}$} & \multirow{2}{*}{-62.59} & \multirow{2}{*}{35.82} \\
\hline & SMKN 2 & & & & & & & & \\
\hline \multirow{2}{*}{4} & TVRI & \multirow[t]{2}{*}{20} & \multirow[t]{2}{*}{28} & \multirow[t]{2}{*}{30} & \multirow{2}{*}{7.50} & \multirow{2}{*}{7.50} & \multirow{2}{*}{$\begin{array}{l}132 . \\
40\end{array}$} & \multirow[t]{2}{*}{-69.40} & \multirow{2}{*}{35.65} \\
\hline & Kel. Juata Permai & & & & & & & & \\
\hline
\end{tabular}

Dari hasil perhitungan pada tabel 4.5 diatas, dapat disimpulkan bahwa, setiap jaringan backhaul bisa terkoneksi dengan baik dan telah memenuhi standar yang dan aturan yang berlaku di Indonesia.

\section{Perhitungan Link Budget untuk Wi-Fi}

Dalam perencanaan ini jaringan WiFI digunakan sebagai jaringan yang langsung bisa terkoneksi dengan pengguna, jaringan yang diperoleh dari jaringan backhaul 5,8 GHz dan di konversi menjadi 2,4 GHz. Pada perhitungan link budget pada jaringan WiFI, maka parameter yang digunakan yaitu menggunakan asumsi tinggi antena pengirim, $h_{b}=20 \mathrm{~m}$ Tinggi antena penerima $(\mathrm{CPE}), \mathrm{h}_{\mathrm{cpe}}=5 \mathrm{~m}$, sehingga didapat redaman pada kabel sebesar $\mathrm{c}$ dan $\mathrm{L}_{\mathrm{r}}=1,6 \mathrm{~dB}$. Kemudian untuk nilai penguatan antena penerima yang akan digunakan adalah $\mathrm{G}_{\mathrm{R}}=15 \mathrm{dBi}$. Berikut adalah hasil perhitungan luasan sel yang tercantum pada tabel 4.6, dengan menggunakan antena omnidirectional dengan nilai penguatan sebesar $\mathrm{G} \tau=15 \mathrm{dBi}$ dan antena sektoral $120^{\circ}$ dengan nilai penguatan sebesar $\mathrm{G}_{\mathrm{T}}=$ $14 \mathrm{dBi}$.

Tabel 4.6 Perhitungan Link Budget dan Luasan Sel

\begin{tabular}{|c|c|c|c|c|c|c|c|}
\hline \multirow{2}{*}{ Sel } & \multirow{2}{*}{$\begin{array}{l}\text { Fre } \\
\text { kuensi } \\
\text { MHz) }\end{array}$} & \multirow{2}{*}{$\begin{array}{l}\text { EIRP } \\
(\mathrm{dBm})\end{array}$} & \multirow{2}{*}{$\begin{array}{l}\text { RSL } \\
\text { (dB) }\end{array}$} & \multirow{2}{*}{$\begin{array}{l}\text { FSL } \\
(\mathrm{dB})\end{array}$} & \multirow{2}{*}{$\begin{array}{l}\text { Jarak } \\
(\mathrm{km})\end{array}$} & \multicolumn{2}{|c|}{$\begin{array}{c}\text { Luasan Sel } \\
\left(\mathrm{km}^{\wedge} 2\right)\end{array}$} \\
\hline & & & & & & $\begin{array}{l}\text { Ling } \\
\text { karan }\end{array}$ & $\begin{array}{l}\text { Hexa } \\
\text { gonal }\end{array}$ \\
\hline TVRI & 2412 & 30.10 & -65 & 108.50 & 2.63 & 21.74 & 17.98 \\
\hline SMKN 2 & 2437 & 30.10 & -65 & 108.50 & 2.60 & 21.29 & 17.62 \\
\hline $\begin{array}{l}\text { Kec. Tarakan } \\
\text { Timur } 1\end{array}$ & 2437 & 29.10 & -65 & 107.50 & 2.32 & - & 13.99 \\
\hline $\begin{array}{l}\text { Kec. Tarakan } \\
\text { Timur } 2\end{array}$ & 2462 & 29.10 & -65 & 107.50 & 2.30 & - & 13.71 \\
\hline $\begin{array}{l}\text { BTS Pantai } \\
\text { Amal } 1\end{array}$ & 2437 & 25.10 & -65 & 103.50 & 1.46 & - & 5.57 \\
\hline $\begin{array}{l}\text { BTS Pantai } \\
\text { Amal } 2\end{array}$ & 2462 & 25.10 & -65 & 103.50 & 1.45 & - & 5.46 \\
\hline $\begin{array}{l}\text { Kec. Tarakan } \\
\text { Utara }\end{array}$ & 2412 & 30.10 & -65 & 108.50 & 2.63 & 21.74 & 17.98 \\
\hline $\begin{array}{l}\text { Kel. Juata } \\
\text { Permai }\end{array}$ & 2462 & 30.10 & -65 & 108.50 & 2.58 & 20.86 & 17.26 \\
\hline
\end{tabular}

Dari hasil perhitungan pada tabel 4.6 diatas, maka dapat diketahui seberapa luas jaringan pada setiap sel, sehingga dapat diketahui daerah mana saja yang terjangkau oleh jaringan WiFi.

\section{Desain Jaringan Wireless Metropolitan Area Network di Kota Tarakan}

Dari seluruh hasil perhitungan link budget diatas, maka dapat didesain sebuah jaringan Wireless Metropolitan Area Network di Kota Tarakan seperti pada gambar 4.11 dan gambar 4.10 untuk desain jaringan backhaulnya. 


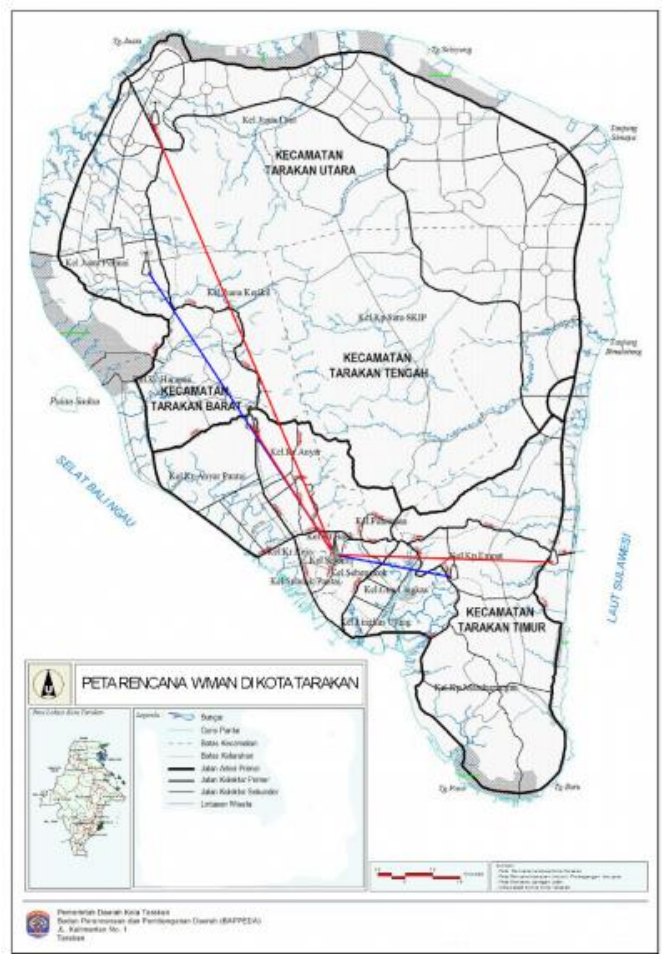

Gambar 4.10 Desain Jaringan Backhaul di Kota Tarakan

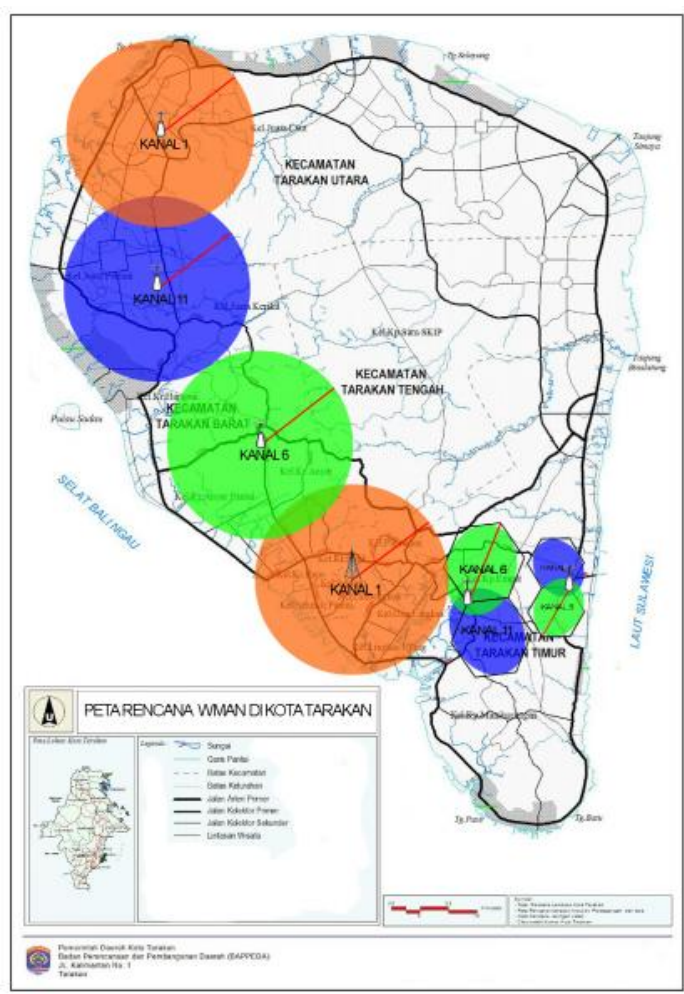

Gambar 4.11 Desain Jaringan WMAN di Kota Tarakan

\section{KESIMPULAN}

Berdasarkan hasil analisis dan perhitungan, maka diambil kesimpulan sebagai berikut :

1. Dalam perencanaan sel-sel kanal komunikasi WiFi didapatlah hasil yang optimal yaitu dengan memanfaatkan 6 menara yang sudah ada di kota Tarakan.

2. Dalam perhitungan link budget maka didapatlah hasil yang telah memenuhi standar dan peraturan yang berlaku di Indonesia dan dapat terkoneksi dengan baik, sehingga para konsumen dapat menggunakan jaringan internet.

3. Dalam menentukan luasan sel, dapat diketahuilah daerahdaerah mana saja yang akan mendapatkan jaringan internet.

4. Dalam mendesain jaringan menggunakan metode topologi bintang pada jaringan backhaul dan pada jaringan WiFi menggunakan metode hexagonal dan lingkaran untuk mengetahui radius pancaran sinyal $\mathrm{WiFi}$ tersebut.

\section{REFERENSI}

Buku Saku Statistik Kota Tarakan, 2006, (www.tarakankota.go.id)

Gunadi Dwi H, 2009, "WiFi (Wireless LAN) Jaringan Komputer Tanpa Kabel”, Penerbit Informatika, Bandung.

International Telecommunication Union Radiocommunication (ITU-R), Recommendation P.530-9, "Propagation data and prediction methods required for the design of terrestrial line-of-sight systems".

Joyoboyo, 2005, "Perencanaan Sistem Wireless Metropolitan Area Network dengan Menggunakan Teknologi Worldwide Interoperability for Microwave Access (WiMAX) Pada Wilayah Daerah Istimewa Yogyakarta", Tugas akhir STT TELKOM, Bandung.

Peraturan Menteri Perhubungan, 2005, "Tentang Penggunaan Pita Frekuensi 2,4 GHz", Jakarta.

Purbo W. Onno, dkk, 2007, "Jaringan Wireless di Dunia Berkembang", Penerbit Andi, Yogyakarta.

Purwanto Budi, 2002, "Link Budget Calculation \& Transponder Management", PT. Satelindo (C) ASSI SATCOM Course.

Wardhana dkk, 2010, "Teknologi Wireless Communication dan Wireless Broadband", Penerbit Andi, Yogyakarta.

(www.aksespoint.com, diakses 1 November 2011)

(www.tp-link.com, diakses 1 November 2011) 